UDC 001.8:004

Ashot GEVORGYAN

\title{
THE ROLE OF SCIENTOMETRIC INDICATORS IN MODERN SCIENTIFIC WORLD
}

\begin{abstract}
The article touches upon one of the most topical and controversial issues of the sphere of modern scientific research: the review, control and guidance of the effectiveness of the scientific activity of the authors through scientometric mechanisms. Drawing parallels between various historical periods and particularly highlighting the importance of the issue in the $20^{\text {th }}$ century, the indirect but important influence and role of the Internet is emphasized. Some proposals and guarantees are also put forward which can slightly alleviate the frequent inequality and inadequacy in the field of assessing and evaluating scientific researches and researchers.

Keywords: scientometrics, refrences, publications, impact factor, h-index, scientific journals, scientific indicators.

Introduction

In modern scientific world the quantitative description of references to the scientific works of the researcher is observed as the most convincing factor of the effectiveness of his scientific activity. Therefore, it seems quite logical that in the context of modern scientific research activity the number of references to their own publications, which is referred to as reference index, is quite important for all the representatives of the scientific community. However, it is worth admitting that researchers, thinkers and philosophers have always cared for the effectiveness of the results of their intellectual and rational activities, that is, in all periods of time researchers have always been interested in the opinion of their "colleagues" and the ways they perceived and evaluated their activities. Although, initially

there were no universal and general standards in this respect, some scholars set out some mechanisms of the differentiation and evaluation of the effectiveness of scientific research activities, which practically existed in all ages with slightly different interpretations and perceptions. If in early scientific and philosophical conceptions the number of works or, as Diogenes Laertius puts it, the number of lines in them (see, for example, Borukhovich, 1976, p. 99), was considered the standard for the effectiveness of the activity of the researcher, the medieval scientific and philosophical minds, in addition to this quantitative indicators, also considered references to authorities, particularly Aristotle. In modern times, in the light of the discredit of Aristotelianism and scholastic traditions, as a criterion for the effectiveness of scientific activities qualitative indicators have been mainly put
\end{abstract}


forth, particularly, the overestimation of the data of experimental researches, based on the best philosophical traditions of Fr. Bacon, J. Locke and other philosophers of the $17^{\text {th }}$ and $18^{\text {th }}$ centuries. However, the further evolution of the scientific activity led to the fact that it was no longer possible to describe, evaluate and value the level of effectiveness of the scientific activity of researchers based on purely general qualitative criteria. Since the beginning of the $20^{\text {th }}$ century within certain scientific and philosophical frames various solutions to the demarcation problem can be observed not only as an attempt to differentiate between scientific and non-scientific knowledge, but also as an initiative to outline further goals to clarify the standards for the quality of science and, consequently, of the effectiveness of the scientific activity of the researcher. Without going into detail of the logic of debates on the demarcation problem, it is worth noting that in the second half of the $20^{\text {th }}$ century the scientific mind on a qualitatively new level formed a new requirement for the evaluation and assessment of the scientific activity, which at the beginning of the 60 s was for the first time interpreted through introduction of quantitative indicators of the references to scientific publications. It is worth noting that by the end of the $19^{\text {th }}$ century one or two attempts had already been made, as a result of which it can be mentioned that the mechanism of quantitative indicators through references had already been tested (Shephard index, index Medicus) (see Gevorgyan, 2016).

Scientometric Issues and the Internet

By the end of the $20^{\text {th }}$ century, the Internet penetrated into all the spheres of human activity, consequently it also penetrated into the sphere of scientific activity. At first sight it may seem that it should not have any connection with the issue in question, however, we must admit that it not only influenced the qualitative decision of the issue of the effectiveness of the scientific activity, but also in the context of quite complex diversities of mutual impacts eventually became one of its most important and influential components. When in 1961 E. Garfield introduced the mechanism to calculate the effectiveness of scientific works through references, the Internet did not even exist, however, in the 90 s of the $20^{\text {th }}$ century the existing interesting innovative information system from the very beginning of its existence evaluated and valued the factor to link web pages together through references, and later the factor to evaluate the qualitative weight and effectiveness of those pages through the number of those references.

Nowadays, it is practically impossible to identify and in terms of priority to definitely evaluate whether the mechanism of scientific references brings qualitative clarification in the domain of online diversity or whether the Internet opportunities guide and dictate the sequence and the process of the actions and steps aimed to increase the effectiveness of the scientific activity. But one thing is clear: it is no more possible to observe the scientific activity separately from the opportunities aimed to evaluate its effectiveness provided by the Internet.

\section{Modern Scientometric Indicators}

In modern scientific world in the role of the standard of the effectiveness of scientific activity it is accepted to mention various factors establishing the quantitative characteristics of references. When speaking about the 
reference indicator of scientific articles the so-called impact factor is usually mentioned, which is an important numeric indicator of the effectiveness of the scientific journal. This factor is calculated annually by the Institute of Scientific Information (ISI) (from 1961 onwards) and is published in the "Journal Citation Report".

The calculation of impact factor is done for a three-year period. So, the impact factor of the journal in 2016 is calculated by using the formula $\mathrm{I} 2015=\mathrm{A} / \mathrm{B}$, where $\mathrm{A}$ is the number of those references during 2016 which were made in that journal in the articles published from 2014-2015, and B is the number of articles published in that journal from 2014-2015 (Zhukova, 2013).

The next scientometric indicator which is quite widely spread and famous is the socalled Hirsch index or h-index. It was suggested by an Argentine American physicist Jorge Hirsch in 2005. This index was initially suggested for the evaluation of the effectiveness of the scientific activity of physicists, however, Scopus started to use it as a universal scientometric indicator.

According to h-index, a scholar has an index of $h$, if $h$ out of his $\mathrm{N}$ articles is cited at least $\mathrm{h}$ times, in case when each of the rest $(\mathrm{N}-\mathrm{h})$ articles is cited less than $\mathrm{h}$ times.

In other words, a scholar with an index of $h$ has published $h$ papers each of which has been cited in other papers at least $h$ times.

$\mathrm{H}$-index has its modifications: g-index, $\mathrm{i}$ index, etc. The traditional impact index also has its modifications but they have still to be systematized. After all, all of them are represented as a unit absolutizing the quantitative characteristics of the references to the researcher's work (Bolotov, Kvelidze-Kuznecova, Laptev, \& Mo- rozova, 2014).

The Effectiveness of Scientific Activity

Undoubtedly, this scientometric unit is an extremely important and irreplaceable element in the process of the description, analysis and interpretation of scientific journals, the works of authors and even Universities, the quantitative characteristics of the effectiveness of the scientific activity. However, we should not exaggerate and observe this "tool", as a previously unavailable environment providing the universal, comprehensive and brief description of the science image. Many researchers are sure that the scientometric assumptions based on the number of references can only serve as a means, and in no case can be represented as a complete, systematic standard for the final analysis of the scientific activity. For example, some specialists claim that the effectiveness of the scientific activity of the researcher can be evaluated only by appropriate professional expert groups, which, of course, can use the internationally accepted standard of scientometric indicators as a helping means and as a "necessary tool" (for example, Tomski, 2015 or Orlov, 2013). At least, there is hardly a researcher in the scientific community who will question the argument that the existence of centralized and specialized databases and scientometric indicators is extremely useful and opens wide horizons for the advancement of the scientific mind, as well as helps scholars socialize their ideas and share with a large number of interested audiences. Such claims emphasize the fact that scientific activity cannot and should not be limited. Following this logic, we should agree with the idea that sci- 
ence should strive for some universalization, in terms of some factors and standards should become understandable and available for a large audience. In this respect, there are interesting researches which obviously point the advantages of popular scientific works to digital, published and, consequently in terms of availability, less available works (for example, Epshtein, 2006). However, such claims are unable to turn scientific communities, which are practically separated and delimited by objective barriers, into elements of a single unified system, artificially uniting various scientific fields and spheres which practically have no connection with each other. Even many of the existing modern systems of databases cannot solve this problem. Over the last decade even specialized databases have been split, because those responsible for them realize that they cannot (in fact, it is impossible to) be guided by the same or similar standards to evaluate, compare and describe the effectiveness of researches, journals and scientists representing various fields of science.

The most famous database system, WoS, has long been split into Science Citation Index Expanded, Social Sciences Citation Index, Arts \& Humanities Citation Index and into other subdatabases, as the scientometric databases describing humanitarian and social sciences definitely cannot compete with the databases including natural science, especially medicine and other similar fields of science. However, this does not mean that the field of natural science has the absolute superiority. It just states that in terms of quantitative indicators researches in natural science react to objective developments and changes more quickly. And it could not be otherwise, as natural science is dependent on any minute and less significant transformations of the objective reality, which very often require immediate and urgent solutions. While social-humanitarian researches can react comparatively slowly to such transformations, and in case of reacting can discuss, analyze and interpret the same realities an events for months, even years discovering new platforms and sub-elements.

\section{Instead of Conclusion}

Next to the issues discussed above there is an objectively important sub-issue in modern scientific world. Even surface observations show that in terms of journals registered in leading international scientometric databases, and consequently from the perspective of the effectiveness of the scientific activity of researchers non-English speaking countries are in unfavorable conditions (Sargsyan, Ghazaryan, Iskandaryan, \& Ayvazyan, 2010). The majority of countries try to solve this problem by introducing their own scientometric databases or equivalent systems, which inevitably leads to the increase in the percentage of selfreference. In Armenia such a perspective on the future of scientific researches outlines quite gloomy and vague horizons, especially if we take into account the lack and limitations of specialized scientific journals, conferences and other scientific environments. Of course, there are objective reasons for this, but this justification does not contribute to the increase in the effectiveness of the field of scientific researches. If the peculiarities of national scientific mind were not neglected, the attempts to find systemic solutions to this problem would be efficient, taking into account the international experience. Another solution is to give a boost to the scientific re- 
search trends in cooperation with international researchers. However, taking comprehensive steps to increase the international reputation of local scientific journals is the most important thing, which will give Armenian researchers the opportunity to make the results of their researches available for their colleagues with very low expenses, thus becoming a part of a big global research company.

\section{REFRENCES}

Bolotov, V. A., Kvelidze-Kuznecova, N.N., Laptev, V. V., \& Morozova, S. A. (2014). Indeks Khirsha v rossiiskom indekse nauchnogo citirovaniya (The h-Index in the Russian Science Citation Index, in Russian). Voprosy obrazovaniya № 1, 241-262.

Borukhovich, V. G. (1976). V mire antichnykh svitkov (In the World of Ancient Scrolls, in Russian) (E.D. Frolov, Ed.). Saratov: Izdatel'stvo Saratovskogo universiteta.

Epshtein, V. L. (2006). Kak uvelichit' indeks citirovaniya nauchnoi publikatsii (How to Increase the Citation Index of a Scientific Publication, in Russian). Prob lemy' upravleniya, 6, 83-84.

Gevorgyan, A. (2016). Advanced Scientometric Databases as an Objective Criterion of Scientific Activities. WISDOM, 1(6), 29-32.

doi:10.24234/wisdom.v1i6.60

Orlov, A. I. (2013). Naukometriya i upravlenie nauchnoi deyatel'nost'yu (Scientometrics and Management of Scietific Activity, in Russian). Upravlenie bol'shymi sistemami, 44, 538568.

Sargsyan, Sh., Ghazaryan, N., Iskandaryan, E., \& Ayvazyan, N. (2010). Hayastanyan gitakan parberakanneri azdecut'yan gorc'ony' (Impact Factor of Armenian Scientific Periodicals, in Armenian). 21 Dar, 6, 35-52.

Tomski, G. V. (2015). O naukometricheskikh pokazatelyakh (On Scientometric Indicators, in Russian). CONCORDE, 4., Editions Du JIPTO, 3-25.

Zhukova, I. A. (2013). Indeksy citirovaniya: Vzglyad sotsiologa (Citation Indices: Sociological Point of View, in Russian). Upravlenie bol'shymi sistema$m i, 44,436-452$. 